\title{
P03-03. Protection against SIV by anti HLA class II specific antibody in the macaque model
}

\author{
MJ Robinson*, R Quartey-Papafio, N Almond and M Page
}

Address: Division of Retrovirology, National Institute for Biological Standards and Control, Potters Bar, UK

* Corresponding author

from AIDS Vaccine 2009

Paris, France. 19-22 October 2009

Published: 22 October 2009

Retrovirology 2009, 6(Suppl 3):P20 doi:10.1 186/I742-4690-6-S3-P20

This abstract is available from: http://www.retrovirology.com/content/6/S3/P20

(C) 2009 Robinson et al; licensee BioMed Central Ltd.

\section{Background}

Inactivated SIV vaccines provide potent protection against challenge by SIV in the macaque model. Following evidence that host cell antigens can confer protection, and evidence that this protection can be conveyed to naive macaques in serum transfer experiments, we now show that this protection is due to immunity against HLA class II proteins. Recently it was shown that humans immunised with inactivated virus made an antibody response against HLA class I and II antigens expressed on the surface of the cell line used to grow the virus. Importantly, immunised individuals did not break tolerance to selfantigens. Here we show protection via different epitopes on the HLA class II protein in xeno-immunised macaques that may provide a correlate of protection.

\section{Methods}

Macaques vaccinated with fixed inactivated human T cells (C8166) or murine L cells expressing DR4 were challenged with SIV propagated in a human $\mathrm{T}$ cell line to assess the breadth of protection. Macaque sera were assayed for antibodies reacting with human MHC class II proteins using a luminex assay. Antibody neutralisation data was determined by TZM-bl single round SIV infectivity assay.

\section{Results}

Animals immunised with either C8166 cells or L cells expressing DR4 produced an antibody response that cross reacted with all human MHC class II proteins tested. Those animals that had a high anti class II antibody titre were protected against SIV challenge, and correlated with an ability to neutralise SHIV-W61D grown in C8166 cells in vivo.

\section{Conclusion}

We have previously published data that shows allo-immunisation in humans by whole inactivated virus generates an allo-specific response. Xeno-immunisation of macaques generates a pan specific anti-HLA class II response indicating that anti-framework or conserved regions are immunogenic, and induce a protective immunity. These results suggest that allo-immunisation of macaques is a more appropriate model for evaluating allo-immunisation of humans as an HIV/AIDS vaccine strategy. 